\title{
Prophylactic Role of Curcumin against Aspirin Induced Congestion of Blood Vessels in Kidneys of Adult Female Albino Rats
}

${ }^{1}$ Saba Amjad, ${ }^{2}$ Muhammad Suhail, ${ }^{3}$ Asma Zulfiqar, ${ }^{2}$ Javaid Iqbal, ${ }^{2}$ Tayyaba Muzaffar

${ }^{1}$ Department of Anatomy, UCMD, University of Lahore

${ }^{2}$ Department of Anatomy, Shaikh Zayed Postgraduate Medical Institute, Lahore

${ }^{3}$ Department of Anatomy, Fatima Memorial College of Medicine and Dentistry, Lahore.

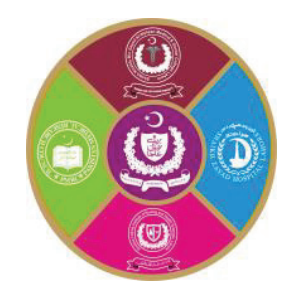

\begin{abstract}
Introduction: Aspirin is the most commonly used non-steroidal anti-inflammatory drug. Curcumin is a chemical component of turmeric powder which is used as a coloring and food flavoring agent. Aims \& Objectives: To evaluate the nephroprotective effects of curcumin on Aspirin induced congestion of blood vessels in kidneys of adult female albino rats. Place and duration of study: Department of Anatomy, Shaikh Zayed Postgraduate Medical Institute, Lahore and study duration was of 30 days. Material \& Methods: 4 groups were made. 15 rats were present in each group and study was conducted for 30 days. Nephrotoxicity was induced with aspirin given by gastric intubation $(200 \mathrm{mg} / \mathrm{kg}$ bodyweight $)$ in positive control group B, experimental groups $C \& D$. Then rats of experimental group $C$ in addition to aspirin received $15 \mathrm{mg} / \mathrm{kg}$ body weight of curcumin and rats of experimental group D received $30 \mathrm{mg} / \mathrm{kg}$ body weight of curcumin by gastric intubation. Results: On histopathological examination, the congestion of blood vessels was present in 11 $(73.3 \%)$ rats in positive control group B followed by $6(40.0 \%)$ and $3(20.0 \%)$ in experimental groups C and $\mathrm{D}$ respectively. This difference among groups was highly significant with $\mathrm{p}$-value $<0.001$. Conclusion: The present study revealed that curcumin decreases the congestion of blood vessels and the results are dose dependent.
\end{abstract}

ABSTRACT

Key words: Aspirin, Curcumin, congestion of blood vessels, kidneys, adult female albino rats

\section{INTRODUCTION}

Aspirin is the most frequently used NSAID all over the world. It produces nephrotoxicity by inhibiting prostaglandin synthesis. ${ }^{1}$ It irreversibly inhibits cyclooxygenase-1 (COX-1) and modifies the enzymatic activity of cyclooxygenase-2 (COX2). ${ }^{2}$ Aspirin causes damage of tubular epithelial cells by ischemia due to vasoconstriction of renal arterioles, atrophic changes in the proximal and distal convoluted tubules in the renal cortex and the inflammatory changes in the renal medulla. ${ }^{3}$

Both immunologic and non-immunologic mechanisms are involved in the development of nephrotoxicity by non-steroidal anti-inflammatory drugs (NSAIDs). Medullary ischemia is the initial event which is produced due to inhibition of prostaglandin synthesis by NSAIDs that reduces medullary blood flow. ${ }^{4}$ Studies have proved that sexually mature female rats are more susceptible to aspirin induced nephrotoxicity than male and immature female rats. ${ }^{5}$ Aspirin is more toxic to females because of lower serum aspirin esterase level which degrade aspirin more slowly. Thus, pharmacologically the nephrotoxic effects of acetyl ester are more in females. ${ }^{6}$ Aspirin is used to treat pain, inflammation and fever. It also has therapeutic uses in the prevention of cardiovascular disease, chemoprevention of colorectal cancer, the prevention and treatment of Alzheimer's disease and the treatment of reflux esophagitis when NSAIDs are coupled with acid inhibitors. ${ }^{7}$ It causes gastrointestinal disturbances which include nausea, vomiting, heartburn, indigestion, peptic ulcers as well as major gastrointestinal bleed; melena that requires transfusion or hematemesis and renal failure. Aspirin is contraindicated in patients with peptic ulcer disease, gastritis or duodenitis, gastrointestinal bleeding, alcoholism, and cerebral hemorrhage. $^{8}$

Curcumin is a chemical component of turmeric powder obtained from the rhizome of the plant Curcuma Longa. ${ }^{9}$ Turmeric belongs to a family of 
Zingiberaceae. ${ }^{10}$ It is used as a coloring and food flavoring agent ${ }^{11} \&$ being extensively cultivated in Asian countries, mainly in India and China. ${ }^{12}$ The curcuminoids that are derived from turmeric are: $71.5 \%$ curcumin-I (Diferuloylmethane), 19.4\% curcumin II (demethoxycurcumin) and 9.1\% curcumin III (bisdemethoxycurcumin). ${ }^{13,14}$ It also contains volatile oils (Tumerone, atlantone and zingiberone), sugars, proteins and resins. The curcuminoid complex is also called as "Indian Saffron". ${ }^{15}$ Curcumin exhibits anti-inflammatory, anti-atherosclerotic, ${ }^{16}$ antioxidant, anti-bacterial, antispasmodic, anti-human immunodeficiency virus, anti-protozoal and nematocidal activities. ${ }^{12}$ In one study the beneficial effects of curcumin were studied for the treatment of swelling and sprains caused by injury. ${ }^{17}$ Curcumin promotes wound healing and muscle regeneration; inhibits scarring, gall stone formation and cataract; prevents liver injury and kidney toxicity; septic shock, cardiovascular disease, inflammatory bowel disease, ${ }^{18}$ and arthritis. ${ }^{19}$ It inhibits free radical generation and lipid peroxidation and has scavenging abilities, thus protects DNA from oxidative injury. ${ }^{20}$ It reduces the profibrotic cytokines, VEGF, transforming growth factor-beta (TGF- $\beta$ ), connective tissue growth factor (CTGF), osteopontin and extracellular matrix proteins; fibronectin and collagen IV. It also prevents structural damage by lowering glomerulosclerosis Index (GI), tubulointerstitial fibrosis and arteriolopathy. ${ }^{21}$ Curcumin down regulates the activity of drug metabolizing enzymes cytochrome P450 that can lead to toxicity of some drugs. ${ }^{22}$ Numerous evidences indicate that curcumin is a bifunctional antioxidant with both direct and indirect antioxidant effects. It scavenges ROS and in Nrf-2 dependent way induces the expression of cytoprotective proteins. ${ }^{23}$

Curcumin is very commonly used as a food flavoring product, the present study was designed to evaluate the prophylactic effects of curcumin against aspirin induced congestion of blood vessels in adult female albino rats.

\section{MATERIAL AND METHODS}

This experimental study was conducted in the Department of Anatomy, Shaikh Zayed Postgraduate Medical Institute, Lahore.

All rats were kept in cages in the animal house of the Department of Anatomy, PGMI, Lahore. The rats were allowed free access to food and water. A 12 hourly light: dark cycle was maintained at room temperature $27^{\circ} \mathrm{C}$. After acclimatization for 15 days, these rats were kept in separate cages divided into 4 groups $\mathrm{A}, \mathrm{B}, \mathrm{C}$ and $\mathrm{D}$ with proper labeling. 15 rats were present in each group. Body weight was measured before and at the end of experiment. Blood samples were taken from the rat's tail before the experiment and then on $15^{\text {th }}$ and $30^{\text {th }}$ day of experiment, for assay of creatinine of all four groups. A lignocaine cream as a local anaesthetic was applied to the site 30 minutes prior to blood sampling. ${ }^{24}$

Turmeric extract was prepared from PCSIR laboratory, Lahore. Quantification of extract was done through Gas Chromatography-Mass Spectrometry (GC-MS) from Chemistry Department of Forman Christian College, Lahore.

Turmeric extract was given to the rats through orogastric intubation. All the groups had 15 female wistar rats.

Group A (Healthy Control): The rats received distilled water $10 \mathrm{ml} / \mathrm{kg}$ body weight $/$ day.

Group B (Positive Control): The rats were fed with $100 \mathrm{mg} / \mathrm{kg}$ body weight/day of aspirin for 30 days.

Group C (Experimental I): The rats were fed with $100 \mathrm{mg} / \mathrm{kg}$ body weight/day of aspirin and $15 \mathrm{mg} / \mathrm{kg}$ body weight of curcumin simultaneously for 30 days.

Group D (Experimental II): The rats were fed with $100 \mathrm{mg} / \mathrm{kg}$ body weight/day of aspirin and $30 \mathrm{mg} / \mathrm{kg}$ body weight of curcumin simultaneously for 30 days.

After dissection, the kidneys were removed and studied histologically for congestion of blood vessels.

\section{Statistical analysis:}

Data was entered and analyzed by using SPSS 22.0. The qualitative data for changes in blood vessels was reported by using frequency and percentage of each group. Comparison among groups was made by using Chi-square test. P-value $\leq 0.05$ was considered significant.

\section{RESULTS}

The blood vessels appeared normal in control group A (Fig-1) while congestion of blood vessels was present in $11(73.3 \%)$ rats in positive control group B followed by $6(40.0 \%)$ and $3(20.0 \%)$ in experimental groups $\mathrm{C}$ and $\mathrm{D}$ respectively (Fig$2,3 \& 4)$. This difference among groups was highly significant with $\mathrm{p}$-value $<0.001$. (Table- 1 ) 


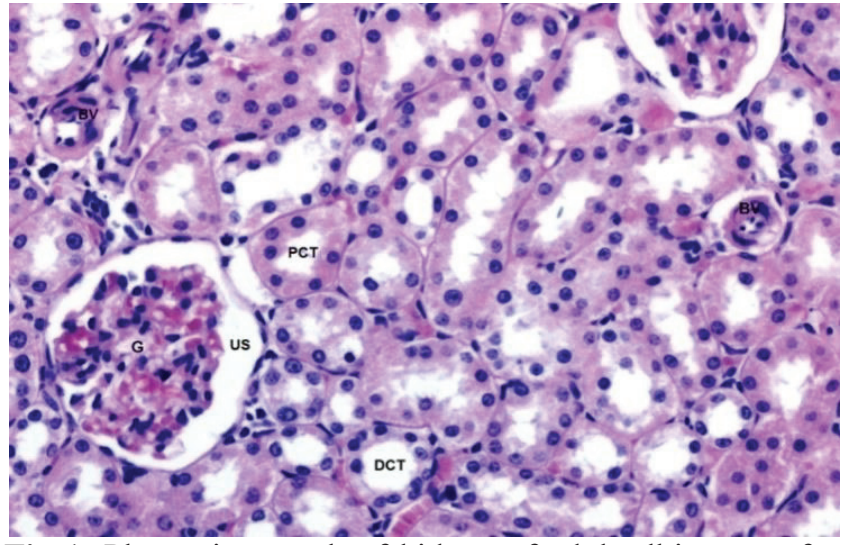

Fig-1: Photomicrograph of kidney of adult albino rat of control group A showing: Glomerulus (G), Urinary space (US), Blood vessel (BV), Proximal convoluted tubule (PCT) and Distal convoluted tubule (DCT) (H\&E, 20x)

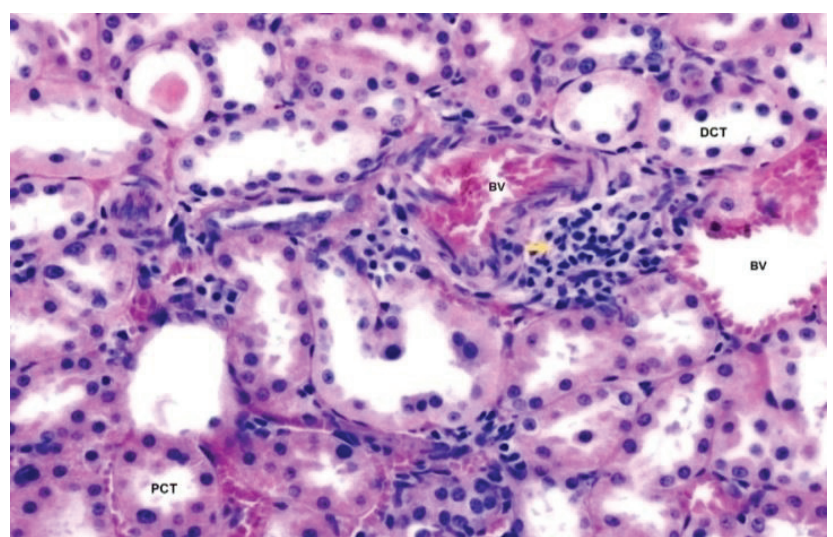

Fig-2: Photomicrograph of kidney of adult albino rat of positive control group B showing: Proximal convoluted tubule (PCT), Distal convoluted tubule (DCT), Blood vessel (BV) with marked congestion and presence of mononuclear cell infiltrate (yellow arrow) in the interstitium. (H\&E, 20x)

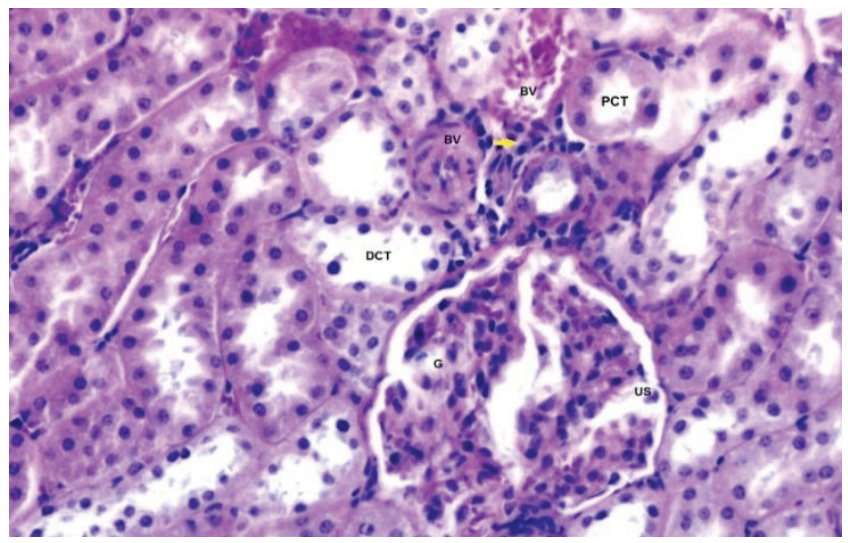

Fig-3: Photomicrograph of kidney of adult albino rat of experimental group $\mathrm{C}$ showing: Glomerulus (G), Urinary space (US), Proximal convoluted tubule (PCT), Distal convoluted tubule (DCT), Blood vessel (BV) with congestion and presence of less mononuclear cell infiltrate (yellow arrow) in the interstitium. (H\&E, 20x)

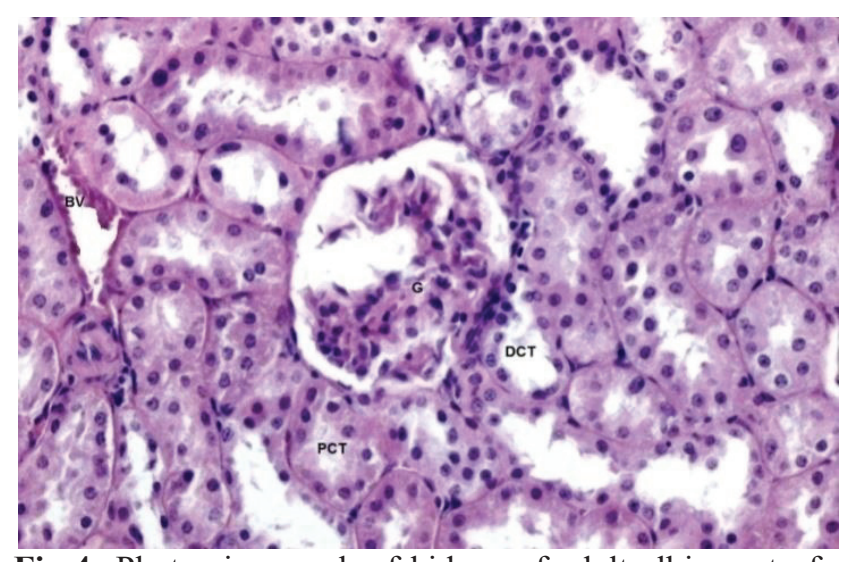

Fig-4: Photomicrograph of kidney of adult albino rat of experimental group D showing: Glomerulus $(\mathrm{G})$, Proximal convoluted tubule (PCT), Distal convoluted tubule (DCT) and Blood vessel (BV) with less congestion. (H\&E, 20x)

\begin{tabular}{|l|c|c|c|c|c|c|}
\hline \multirow{2}{*}{} & \multicolumn{5}{|c|}{ Congestion of blood vessels } \\
\cline { 2 - 7 } & Present & \multicolumn{2}{c|}{ Absent } & \multicolumn{2}{c|}{ Total } \\
\cline { 2 - 7 } & $\mathbf{N}$ & $\%$ & $\mathbf{N}$ & $\%$ & N & \\
\hline Group A & 0 & 0.0 & 15 & 100.0 & 15 & 100.0 \\
\hline Group B & 11 & 73.3 & 4 & 26.7 & 15 & 100.0 \\
\hline Group C & 6 & 40.0 & 9 & 60.0 & 15 & 100.0 \\
\hline Group D & 3 & 20.0 & 12 & 80.0 & 15 & 100.0 \\
\hline Chi-square $=19.8$ & & \multicolumn{4}{c|}{ p-value $<0.001$} \\
\hline
\end{tabular}

Table-1: Comparison of congestion of blood vessels among control groups given aspirin and experimental groups given aspirin \& curcumin

When group wise comparison of congestion of blood vessels was made, it was observed that the positive control group B and experimental group C had significantly higher number of rats with congestion of blood vessels as compared to control group A with p-values $<0.001$ and 0.017 respectively. The experimental group $\mathrm{D}$ had insignificant difference from control group A with p-value 0.224. Similarly, the positive control group B had significantly higher number of rats with congested blood vessels as compared to experimental group D and the p-value was 0.010 . The positive control group $\mathrm{B}$ had insignificant difference from experimental group $\mathrm{C}$ with $\mathrm{p}$-value 0.141. (Table-2 \& Fig-5) 


\begin{tabular}{|c|l|c|c|c|}
\hline $\begin{array}{c}\text { (I) } \\
\text { Group }\end{array}$ & $\begin{array}{c}\text { (J) } \\
\text { Group }\end{array}$ & $\begin{array}{c}\text { Chi- } \\
\text { square }\end{array}$ & Df & P-value \\
\hline \multirow{3}{*}{ Group A } & Group B & 14.35 & 1 & $<0.001^{* *}$ \\
\cline { 2 - 5 } & Group C & 5.21 & 1 & $0.017^{*}$ \\
\cline { 2 - 5 } & Group D & 1.48 & 1 & $0.224+$ \\
\hline \multirow{2}{*}{ Group B } & Group C & 2.17 & 1 & $0.141+$ \\
\cline { 2 - 5 } & Group D & 6.56 & 1 & $0.010^{*}$ \\
\hline Group C & Group D & 0.64 & 1 & $0.427+$ \\
\hline
\end{tabular}

Table-2: Group wise comparison of congestion of blood vessels among control groups given aspirin and experimental groups given aspirin \& curcumin (by using chi-square)

KEY

A Control Group of rats

B Positive control Group of rats

C Experimental Group I of rats

D Experimental Group II of rats

$\mathrm{N} \quad$ Number of rats in each group

Df Degrees of freedom

** Highly significant difference $(\mathrm{P}<0.001)$

* $\quad$ Significant difference $(\mathrm{P}<0.05)$

$+\quad$ Insignificant difference $(\mathrm{P}>0.05)$

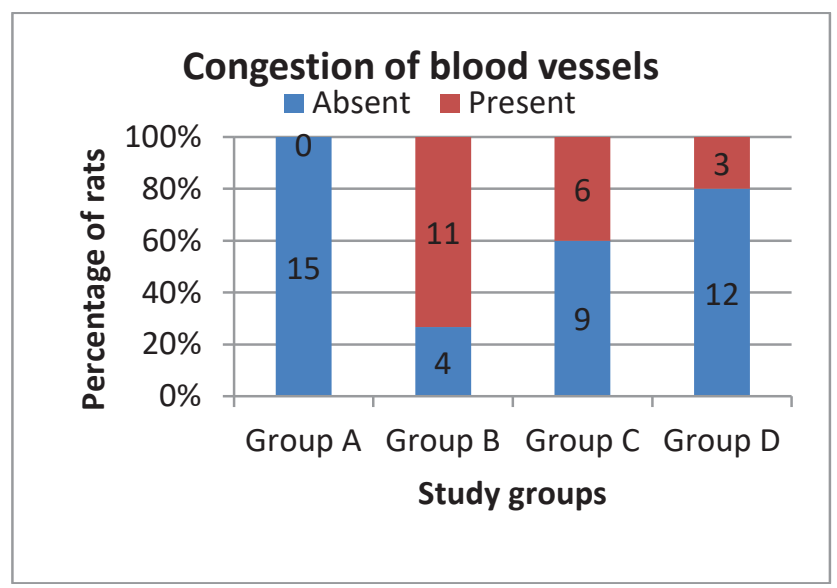

Fig-5: Graphic comparison of congestion of blood vessels among control groups given aspirin and experimental groups given aspirin \& curcumin

\section{DISCUSSION}

Aspirin is the most widely used NSAID that shows versatile purposes such as an anti-inflammatory; in joint diseases, anti-platelet; in cardiovascular diseases, anti-pyretic \& analgesic agents. ${ }^{3,8}$ Curcumin is a spice, additive and a pigment commonly used in Asia. ${ }^{25}$

In the present study the congestion of blood vessels was present in more number of rats in positive control group B followed by experimental group C and experimental group $\mathrm{D}$ respectively. The difference among groups was highly significant with p-value $<0.001$. (Table-1)It has been explained by the Soliman et al who reported that curcumin ameliorated the congestion of renal blood vessels by reducing inflammatory process. ${ }^{26}$ The congestion of blood vessels might be due to the dilatation and hyperemia of blood vessels with focal hemorrhage and mono nuclear cell infiltration. The vascular injury caused by inflammation leads to endothelial cell dysfunction stimulating smooth muscle proliferation and synthesis of associated matrix. ${ }^{27}$

\section{CONCLUSION}

The results of the present study indicated that the co-treatment of aspirin with the ethanolic extract of turmeric prevented aspirin induced congestion of blood vessels in adult female albino rats.

\section{REFERENCES}

1. Fuster V, Sweeny JM. Aspirin a historical and contemporary therapeutic overview. Circulation. 2011; 123(7):768-78.

2. Aspirin 2014 [updated 2014 april 07]. Available from: en.wikipedia.org/wiki/Aspirin

3. Jain Neha, Shrivastava Renu, Raghuwanshi Arun K and Shrivastava Vinoy K. Aspirin induced changes in serum ACP, ALP, GOT, GPT, BILIRUBIN and CREATININE in correlation with histopathological changes in liver and kidney of female albino rat. Int J App Pharm. 2012; (4):9-11

4. Ejaz P, Bhojani K, Joshi V. NSAIDs and kidney. JAPI. 2004; 52:632-9.

5. Nanra RS, Kincaid-Smith P. Papillary necrosis in rats caused by aspirin and aspirin-containing mixtures. British medical journal. 1970; 3(5722):559.

6. Menguy R, Desbaillets L, Masters YF, Okabe S. Evidence for a sex-linked difference in aspirin metabolism. 1972.

7. Vainio H, Morgan G. Aspirin for the second hundred years: new uses for an old drug. Pharmacology \& toxicology. 1997; 81(4):151-2.

8. Awtry EH, Loscalzo J. Aspirin. Circulation. 2000; 101(10):1206-18.

9. Aggarval B, Kumar A, Bharti A. Anticancer potential of curcumin: preclinical and clinical studies. Anticancer Res.2003; 23:363-398.

10. Shimatsu A, Kakeya H, Imaizumi A, Morimoto T, Kanai M, Maeda S. Clinical application of "curcumin", a multi-functional substance. AntiAging Med. 2012; 9:43-51.

11. Li S, Yuan W, Deng G, Wang P, Yang P, Aggarwal BB. Chemical composition and 
product quality control of turmeric (Curcuma longa L.). Pharmaceutical Crops. 2011; 2:28-54.

12. Araujo C, Leon L. Biological activities of Curcuma longa L. Memórias do Instituto Oswaldo Cruz. 2001; 96:723-8.

13. Li S, Yuan W, Deng G, Wang P, Yang P, Aggarwal BB. Chemical composition and product quality control of turmeric (Curcuma longa L.). Pharmaceutical Crops. 2011; 2:28-54.

14. Chattopadhyay I, Biswas K, Bandyopadhyay U, Banerjee RK. Turmeric and curcumin: Biological actions and medicinal applications. Current science. 2004; 87:44-53.

15. Julie S, Jurenka M. Anti-inflammatory Properties of Curcumin, a Major Constituent. Alternative Medicine Review. 2009;14:141-153.

16. Aggarwal BB, Harikumar KB. Potential therapeutic effects of curcumin, the antiinflammatory agent, against neurodegenerative, cardiovascular, pulmonary, metabolic, autoimmune and neoplastic diseases. The international journal of biochemistry \& cell biology. 2009; 41:40-59.

17. Ammon H, Wahl M. Pharmacology of Curcuma longa. Planta medica. 1991; 57(1):1.

18. Beevers CS, Huang S. Pharmacological and clinical properties of curcumin. Botanics: Targets Ther. 2011; 1:5-18.

19. Khanna D, Sethi G, Ahn KS, Pandey MK, Kunnumakkara AB, Sung B, et al. Natural products as a gold mine for arthritis treatment. Current Opinion in Pharmacology. 2007; 7:34451.

20. Sikora E, Bielak-Zmijewska A, Piwocka K, Janusz S, Radziszewska E. Inhibition of proliferation and apoptosis of human and rat $\mathrm{T}$ lymphocytes by curcumin, a curry pigment. Biochemical pharmacology. 1997; 54:899-907.

21. Epstein J, Sanderson IR, MacDonald TT. Curcumin as a therapeutic agent: the evidence from in vitro, animal and human studies. British journal of nutrition. 2010; 103:1545-57.

22. Burgos-Morón E, Calderón-Montaño JM, Salvador J, Robles A, López-Lázaro M. The dark side of curcumin. International Journal of Cancer. 2010; 126:1771-5.

23. Tapia E, Soto V, Ortiz-Vega KM, ZarcoMárquez G, Molina-Jijón E, Cristóbal-García $M$, et al. Curcumin induces Nrf2 nuclear translocation and prevents glomerular hypertension, hyper filtration, oxidant stress, and the decrease in antioxidant enzymes in 5/6 nephrectomized rats. Oxidative medicine and cellular longevity. 2012; 2012.
24. Flecknell P, Liles J, Williamson H. The use of lignocaine-prilocaine local anaesthetic cream for pain-free venepuncture in laboratory animals. Laboratory Animals. 1990; 24:142-6.

25. Coca SG, Singanamala S, Parikh CR. Chronic kidney disease after acute kidney injury: a systematic review and meta-analysis. Kidney international. 2012; 81(5):442-8.

26. Soliman MM, Baiomy AA, Yassin MH. Molecular and histopathological study on the ameliorative effects of curcumin against lead acetate-induced hepatotoxicity and nephrototoxicity in Wistar rats. Biological trace element research. 2015; 167(1):91-102.

27. Stricker TP, Kumar V, Maitra A, Schoen FJ, Mitchell RN, Aster JC. Robbins Basic Pathology. Neoplasia. 2007; 173:52.

\section{The Authors:}

Dr. Saba Amjad,

Assistant Professor,

Department of Anatomy,

UCMD, University of Lahore.

Prof. Muhammad Suhail

Head, Department of Anatomy, FPGMI, Shaikh Zayed Medical Complex,

Lahore.

Dr. Asma Zulfiqar

Assistant Professor,

Department of Anatomy,

Fatima Memorial College of Medicine \& Dentistry,

Lahore.

Dr. Javaid Iqbal

Associate Professor,

Department of Anatomy,

Shaikh Zayed Medical Complex, Lahore.

Dr. Tayyaba Muzaffar,

Assistant Professor,

Department of Anatomy,

Shaikh Zayed Medical Complex, Lahore.

\section{Corresponding Author:}

Dr. Saba Amjad,

Assistant Professor,

Department of Anatomy,

UCMD, University of Lahore.

E-mail: dr.saba14@hotmail.com 